\title{
Defect Minimization in Casting through Process Improvement-A Literature Review
}

\author{
Mr. Patil Sachin S. ${ }^{1}$, Prof. Naik Girish R. ${ }^{2}$ \\ P.G. Student, Department of Production Engineering, KIT's College of Engg, Kolhapur, India ${ }^{I}$ \\ Associate Professor, Dept. of Production Engineering, KIT's College of Engg, Kolhapur, India ${ }^{2}$
}

\begin{abstract}
In India many foundries have followed conventional and manual operations. Foundry industries suffer from poor quality and productivity due to large number of process parameters combined with lower penetration of automation and shortage of skilled worker. Mould shifting, sand inclusions, poor surface finish, shrinkage, porosity, cold shut and flash are common casting defects in casting. Since casting process involves complex interaction among various parameters and operations related to metal composition, method designs, melting, pouring, shake-out, fettling and machining and hence need to improve. This Paper prescribes comprehensive review of work pertaining to process improvement techniques used for defect minimisation in casting.
\end{abstract}

Keywords: Casting design, Casting defect, Cause of defects, Yield improvement, Process improvement.

\section{Introduction}

Green sand casting process is a versatile process because it can be used for casting of most metals with high melting point temperatures like copper, cast iron. Several types of defects may occur during casting, considerably reducing the total output of castings. Defects may be defined as those characteristics that create a deficiency or imperfection differing to the quality specifications imposed by the design and the service requirements. Casting defect analysis is the process of finding root causes of defects and taking necessary steps to reduce the defects and improve the casting yield. Minor defect can be corrected easily where as major defects require significant changes in process at high cost [4].

Foundry industries are suffering from poor quality and productivity. Large numbers of process parameters are responsible for cost of poor quality. Global buyers demand defect free casting and strikes delivery schedule, which foundries are finding very difficult to meet. Casting defect results in increased cost and lower morale of shop floor personnel. The defects need to be diagnosed correctly for appropriate remedial measure; otherwise new defects may be introduced [9].

Process improvement is about resolving global issues or outcomes for the whole system of process. It's about prioritizing problems and fixing only those that improve global outcomes. It is not about fixing any problem that arises. Yet, human nature being what it is demonstrates that people spend $80 \%$ of their time on solving problems and only $20 \%$ on improving the process [19].

\section{Casting Process and Defects.}

The steps involved in casting process are shown in following figure:-

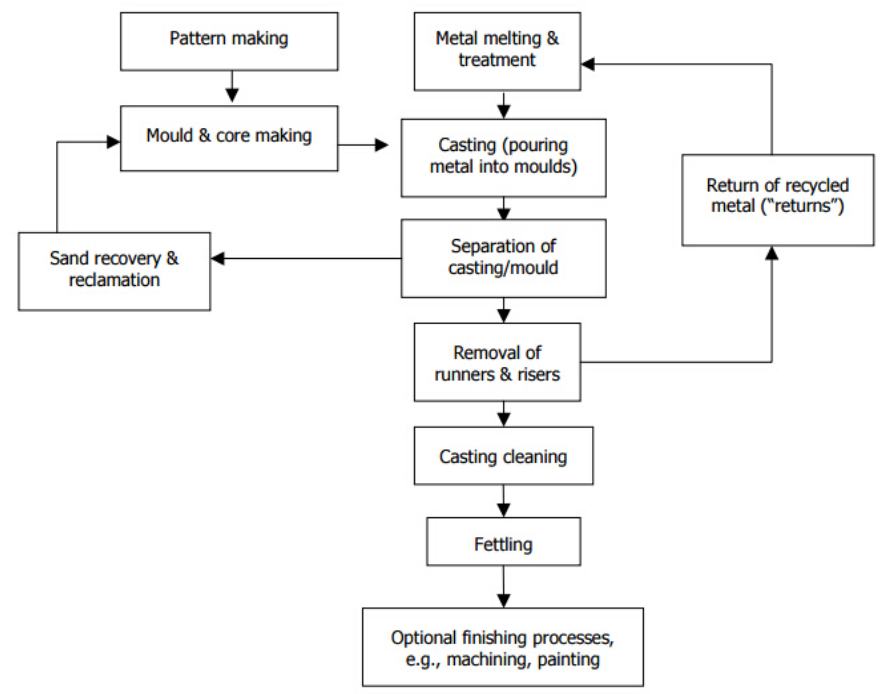


Defect Minimization in Casting through Process Improvement-A Literature Review

Defects occurred in casting process are broadly classified as,

\begin{tabular}{|c|c|c|}
\hline \multicolumn{2}{|c|}{ Casting Defects } \\
\hline Surface defect & Internal Defect & Visible Defects \\
\hline Blow, & Blowholes, & Wash, \\
Scar, & Porosity, & Rat tail, \\
Blister, & Pinholes, & Swell, \\
Drop, & Inclusion, & Misrun, \\
Scab, & Dross. & Cold shut, \\
Penetration, & & Hot tear, \\
Buckle. & & Shrinkage. \\
\hline
\end{tabular}

\section{Literature Review}

Mostly casting defects are concerned with process parameters. Hence one has to control the process parameter to achieve zero defect parts. For controlling process parameter it is essential to have knowledge about effect of process parameter on casting and their influence on defect. Number of researchers has worked for defect minimisation through process improvement using various tools. A brief review discussed further.

Narayanswamy and Natrajan [1] reviewed various casting defects. They categorise defects into filling related defects (FRD), shape related defects (SRD), Thermal defects (TD) and defects by Appearance. The monthly percentage of rejection due to these defects is varying from $12.86 \%$ to $15.01 \%$. The filling related defects are further classified as sand inclusion, rough surface, scabbing, blow holes, chill blow, clay ball hole, sand fusion, and pin holes. Sand related defects are also further classified as mould lift, mould broken, and shift, leakage. The defects by appearance are categorized as DBS blast core missing, swelling, and no core. Out of these defects the filling related defects are to be given importance for the analysis and it is mainly due to the quality of sand. The shape related defects, defects by appearance and thermal defects are due to various factors in mould making process and melting process. Using the modern method and suitable techniques, it is really a boon for the foundry sector to produce quality casting to satisfy the customer requirement. They concluded that quality of castings depends on quality of sand, method of operation, quality of molten metal and environmental conditions etc.

Dr. Shivappa D.N [2] studied TSB Castings revealed that the contribution of the four prominent defects in casting rejections are sand drop, blow hole, mismatch, and oversize. It was noticed that these defects are frequently occurring at particular locations. Systematic analysis were carried out to understand the reasons for defects occurrence and the reasons identified are; The causes of sand drop were found due to improper cleaning of mould in the areas around chills and mould interface, sleeve, and breaker core. Blow holes occurrence around long member is due to failure to connect flow off in the gating design. The mismatch of castings is due to lack of locators and improper setting of cores. Casting oversize is due to mould lift and mould bulging. Remedial measures identified to overcome the above defects are; (i) Sand Drop: Proper cleaning of the mould before closing, ensure that sand don't enter into the sleeve, replace nobake core with shell core, provide pads at bottom face, and modified the loose piece design to avoid core crushing. (ii) Blow Hole: Modification of gating system; flow offs are to be directly connected on top surface of long member. (iii) Mismatch: Provided six locators for proper setting of cores - three are of metallic and three are self-locators. (iv)Oversize: Clamp the moulds properly to withstand the pouring pressure. Production trials were carried out in the foundry for four months period by incorporating the above remedial measures and validated. Outcome of the results showed substantial reduction in rejection of castings.

Joshi and Jugulkar [3] Used Pareto principle and cause effect diagram to identify and evaluate different defects and causes for these defects responsible for rejection of components at different stages of manual casting operations. The correct identification of the casting defect at initial stage is very useful for taking remedial actions. This paper presents the systemic approaches to find cause of defects occurred due to manual operations. From the analysis it was found that the manual metal casting operations are done with some negligence and carelessness. So by suggesting some other remedial issues and by implementing possible of them reduces total rejection more than $30 \%$.If automation is implemented it reduces defects by more than $70 \%$. This systematic study proves that by means of effective analysis of tools and processes, it is possible to control the casting defects.

Jadhav B. and Jadhav S [4] have focused on Cold Shut as a casting defect for analysis. Casting production involves various processes which include pattern making, moulding, core making, melting pouring, shell breaking, shot blasting etc. It is almost impossible to produce defect free castings. Occurrence of the defect may involve single or multiple causes. These causes can be minimized through systematic procedure. The paper represents procedure to analyse and minimize casting defect Cold shut in automobile cylinder block of grey cast iron Grade FG150. This paper represents the defect reduction by controlling alloy composition and pouring temperature. The seven quality control methodology is used to analyse and reduce defects which includes check sheet, pareto analysis, cause effect diagram, flow chart, scatter diagram, histogram and control chart. 
Jain and Rajput [5] investigated Al alloy to minimise defects using seven QC tools. Their study shows the systematic approach to find the root cause of major defects in aluminium castings using defect diagnostic approach as well as cause and effect diagram. To obtain more detailed and effective feedback control during casting of Al-alloy wheel, a process model for the production line was constructed. By help of this diagram the causes of defects and remedies can be pointed. From parato diagram it was found that major rejections are due to shrinkage, cracks and inclusions .By use of check sheets it was seen that various shrinkages resulted in no.of rejections. Using histogram it was noted that the hub shrinkages were more compared to rim and spoke shrinkages.

Vante and Naik [6] focus on better control to solve the problem of dimensional variations in 3 cylinder metric block casting. Quality improvement is achieved by using quality control tools. A proper methodology is formed consisting of various quality control tools such as Pareto analysis, Ishikawa diagram (cause and effect diagram), brainstorming, why-why analysis. After implementation of this methodology a better control over the process can be obtained. Detailed analysis of root cause results into the permanent solution to the problem. Successful implementation of the remedies results into reduced rejection rate of casting and quality improvement.

Kinagi and Dr.Mench [7] analysed casting defects like cold shut and blow holes by combining tools of design of experiments and FMEA techniques. Defect analysis is carried using FMEA tool and Pareto analysis to know potential causes of failure and their effects along with correct actions to improve quality strength and productivity. Their main objective is to optimize sand casting process parameter using DOE method through Taguchi method. Taguchi based L9 orthogonal array was used for experimental purpose and analysis was carried out using Minitab software for analysis of mean (ANOM) plot. The optimized levels of selected process parameters obtained by Taguchi method pouring temperature $\left(1380^{\circ} \mathrm{c} \& 1440^{\circ} \mathrm{c}\right)$, inoculants $(0.3)$, moisture-content (3.3), sand-binder ratio(60:1).

Sushil kumar et al [8] analyse casting defects and concluded that, the quality can be improved by Six Sigma i.e. (DMAIC) approach of parameters at the lowest possible cost. It is also possible to identify the optimum levels of signal factors at which, the noise factors effect on the response parameters is less. The outcome of their case study is to optimize the process parameters of the green sand castings process, which contributes to minimize the casting defects. The optimized parameter levels for green sand casting process are moisture content $(4.0 \%)$, green strength $\left(1990 \mathrm{~g} / \mathrm{cm}^{2}\right)$, pouring temperature $\left(1410^{\circ} \mathrm{C}\right)$ and mould hardness number vertical \& horizontal $(72 \& 85)$ respectively.

Mane V.V et al [9] carried out casting defect analysis by using techniques like cause-effect diagrams, design of experiments, if-then rules and artificial neural network. Researcher describes 3-step approach to casting defect identification, analysis and rectification. The defects are classified in terms of their appearance, size, location, consistency and discovery stage and inspection method. This helps in correct identification of defects. For defect analysis, the possible causes are grouped into design, material and process parameters. The effect of suspected cause parameters on casting quality is ascertained through simulation. Based on the results and their interpretation, the optimal values are determined to eliminate defects.

Pude G.C et al [10] Used value stream mapping tools for purposes like, use the tools in identifying, quantifying and minimizing major wastes in a foundry production line to quantify the variety of products generated at each manufacturing processes within the foundry line. To formulate practical means of reducing the identified major wastes by reducing excess inventory, defects and unnecessary activities. The aim of researcher is to reduce lead time for process improvement. The results of process activity mapping shows $23 \%$ waste reduction in the areas of unnecessary inventory, transportation and waiting. For quality filter mapping it is difficult in actual practice to predict or analyse the defects at each foundry processes as the final inspection gives the clear picture of internal defects. But it is possible to reduce the chances of defects at the generic origin sources i.e. at melting, moulding, pouring, finishing and by controlling the melting parameters like pouring time, temperature etc. In their study bottleneck product is identified. The key sources for internal scraps are identified and these are analysed and improvement is carried out in these areas. Future state map revealed that about 700 castings per million are saved from defects. It is however to be noted that there is a significant cost to carry out any required changes but the increased throughput against takt time will pay back for investment.

Murugananthan V.R et al [11] studied problems faced by industry like more process time, lower productivity, time waste in non-value adding activities, excessive movement and handling of material etc. They apply lean principle to the shopfloor. By applying $5 \mathrm{~S}$ technique results in effective organization of the workplace, clean and healthy working atmosphere, elimination of losses connected with more handling improving quality and safety at work. They used VSM to eliminate non-value added activities and to reduce manufacturing lead time. Their proposed process removes drawbacks of old production process.

Santos C A et al [12] represents the development of an algorithm, which incorporates heuristic search techniques for direct application in metallurgical industries, particularly those using continuous casting process 
for the production of steel billets and slabs. That is done to determine the casting objectives of maximum casting rate as a function of casting constraints. These constraints are evaluated with the aid of a heat transfer and solidification model based on the finite deference technique, which has been developed and integrated with a genetic algorithm. The application of heuristic search techniques and a numerical heat transfer model to simulate optimal operating conditions for a steel continuous caster, has been proven to be a powerful tool for managing the continuous casting process. A simulation generated by the intelligent algorithm, when compared to the cooling pattern used in a real slab continuous caster, has shown that the modifications suggested by the model assured ingot quality and can lead to a significant reduction in water consumption, as well as an increase in casting production.

Chatrad B et al [13] studied various defects influencing parameters like melting of the metals, alloy agents, pouring temperature, pouring process and pouring time, impurities present in the ladle, etc. Finally conclude the optimized parameters with minimum casting defects with economic impact of the critical manufacturing operations related to some specific case studies and possible goals have been identified. Percentage of rejections is less at $14200 \mathrm{c}-14800 \mathrm{c}$. Percentages of rejections are increasing at least temperature $1400^{\circ} \mathrm{c}$ and maximum temperature $1480^{\circ} \mathrm{c}$. As the pouring time increases the rate of rejection also increases. As increased handling time which lead to increase in defective component. Porosity and inclusions increased due to the impurity in the ladle and mould due to improper cleaning.

Singh and Kumar [14] Analysed defects of check valve namely cold shut, scab and shrinkage. Reduction of causes of these defects like pouring temperature, permeability, mould hardness and sand particles optimised through Taguchi's method. In their work L9 orthogonal array is used for the trial purpose. The response of the $\mathrm{S} / \mathrm{N}$ Ratio, contribution of different process parameters and relation between $\mathrm{S} / \mathrm{N}$ ratio and the levels of different process parameters is studied and analyzed to obtain optimum process parameters. After implementation various experiments and Testing techniques they concluded that the optimum value of Pouring temperature is $1340^{\circ} \mathrm{c}$, Permeability is $150(\mathrm{No})$, Sand particle Size is 42 AFS and Mould Hardness Number is 91.132 .

Nimbulkar and Dalu [15] worked on gating system design to know last solidifying region in casting and eliminate these defects. They simulate old gating system for productivity and defect and modified the present gating system in new gating system by using Auto-CAST X1 simulation software. They found that initial vertical gating system was not suitable for thick casting components hence proposed horizontal gating and feeding system so that molten metal flow becomes uniform, gases escape easily in to atmosphere. Feeding related defects had been reduced by $30 \%$.

Sarath and Rathish [16] suggested new approach to produce sound FG 260 gray iron casting by computer simulation through experimental validation in a cast iron foundry. The casting process is simulated by using finite element simulation software and results were compared. A simple rectangular plate casting dimension $200 * 100 * 15 \mathrm{~mm}$ is produced with different combination of riser dimensions. To improve the yield and minimise defect, cylindrical riser of of hemispherical bottom width $\mathrm{h} / \mathrm{d}=1.3 \mathrm{was}$ considered. ANSYS simulation software was used to compute solidification time and selection of optimal riser dimensions. It was proven by researchers that hemispherical bottom riser consumes 16-17\% less metal than standard cylindrical side riser. Experimental verification was also done to validate results obtained by simulation.

Choudhari C.M et al [17] observed that solidification simulation enables visualization of the progress of freezing inside a casting and identification of the last freezing regions or hot spots. This facilitated the optimized placement and design of feeders with improvement in yield by $15 \%$ while ensuring casting soundness without expensive and time consuming trial runs. In this case, the thick portion of the component was subjected to shrinkage porosity. It was the root cause for the poor strength which was leading to premature failure of the component. Proper design of gating system helps in achieving the directional solidification leading towards the feeder; thereby solving the problems of premature failure due to junction solidification and incomplete fill due to sudden variations in thickness. Feeder was placed at last solidifying region using AutoCAST-X software. This approach helped in minimizing the solidification related defects, thereby providing a defect free casting. This study shows that simulation can be of great use in optimizing the feeder dimensions and increasing the feeding efficiency of the casting. Both macro-porosity and micro-porosity were identified as $4.47 \mathrm{~cm}^{3}$ with $100 \%$ quality. Quality, feeding yield and feeding efficiency obtained from software were $99.89,84.66$ and $22.82 \%$ respectively.

Dabade and Bhedasgaonkar [18] proposed method of casting defect analysis by combination of design of experiment method and computer aided casting simulation technique. They aimed to find optimal setting of moulding sand and mould related parameters of green sand casting process of wheel hub casting. The optimised levels of selected process parameters obtained by Taguchi method are moisture contain$4.7 \%$, Green compressive strength- $1400 \mathrm{gm} / \mathrm{cm}^{2}$, Permeability Number-140 and Mould hardness number-85.By using this method \% rejection reduced from $10 \%$ to $3.59 \%$.Also they performed analysis of defects like shrinkage porosity by computer aided casting simulation technique. They suggest new gating system especially 
feeder with optimum size and two in numbers such that reduction in shrinkage porosity was observed by $15 \%$ and improvement in yield by $5 \%$.

\section{Conclusion}

The quality of castings depends on quality of sand, method of operation, quality of molten metal etc. To produce defect free casting attention have to be given towards controlling the process parameters. Most of the researchers in their study used Pareto principle and hence seven quality control tools to identify and evaluate different defects and causes for these defects responsible for rejection of components. Some of also use FMEA, Six sigma, Value stream mapping to control process. Many researchers have conducted experiments on sand process parameters using Design of experiments method such as Taguchi method and proved that the reduction in casting defects due to sand process up to $6 \%$. Also use of simulation for simulation of component, shrinkage porosity defect gets eliminated because these are method related defect. The time required is very less for simulation as compared to the conventional method of design of methoding. Visualization of mould filling phenomenon makes the process easy to understand to the user.

\section{Acknowledgments}

The authors would like to present their sincere gratitude towards the faculty of Department of Production Engineering, KIT College of Engineering, Kolhapur.

\section{References}

[1] Narayanswamy.C, Natrajan.K, Review Analysis of Casting Defect with Respect to Indian Standards in Cast Iron foundry, Journal of Chemical and pharmaceutical Science,2(2016)63-68,ISSN:0974-2115.

[2] Dr.Shivappa. D.N, Rohit, Bhattacharya Abhijit, Analysis of Casting defect and Identification of Remedial Measures-A diagnostic Study, International Journal of Engineering Inventions,6(2012)01-05,ISSN:2278-7461.

[3] Joshi Aniruddha, Jugulkar L.M, Investigation and Analysis of Metal Casting Defects and Defect reduction by Using Quality Control Tools, International Journal of Mechanical and Production Engineering,2(2014)87-92,ISSN:2320-2092.

[4] Prof B.R. Jadhav, S.J. Jadhav, Investigation And Analysis Of Cold Shut Casting Defect And Defect Reduction By Using 7 Quality Control Tools, International Journal of Advanced Engineering Research and Studies.(2013)28-30

[5] Jain Shalabh, Rajput Y.S, Minimisation of Defect in Aluminum Alloy Wheel casting Using 7QC Tools, International Journal of Advanced Engineering Research and Technology,3(2015)280-283,ISSN No:2348-8190.

[6] Vante A.B, Naik G.R, Quality Improvement for Dimensional variations in Sand Casting Using Quality Control Tools, International Journal of Innovative Research in Science, Engineering and Technology,4(2015)6917-6926,ISSN:2319-8753.

[7] Kinagi Prasan, Dr.Mench R.G,A Development of Quality in Casting by Minimizing Defects, International Journal of Recent Research in Civil and Mechanical Engineering,1(2014)31-36.

[8] Kumar Sushil, Satsangi P.S, Prajapati D.R, Six Sigma an Exllent Tool For Process Improvement-A case Study, International Journal of Science and Engineering Research,2(2011)1-10,ISSN 2229-5518.

[9] Mane V.V, Sata A, Khire M.Y, New Approach to casting defects classification and analysis supported by simulation, 2011.

[10] Pude G.C, Naik G.R, Naik P.G, Application of Value Stream Mapping Tools For Process Improvement a Case Study in Foundry, Journal of Mechanical and Civil Engineering, ISSN: 2278-1684, PP: 07-12.

[11] Murugananthan V.R, Govindraj K, Sakthimurugan D, Process Planning Through Value Stream Mapping In Foundry, International Journal of Innovative Research in Science, Engineering and Technology,3(2014)1140-1143.ISSN:2319-8753.

[12] Santos C.A, Jaime A.S, Maria C.F, Amauri G, The use of artificial intelligence technique for the optimization of process parameters used in the continuous casting of steel, ELSEVIER,26(2002)1077-1092.

[13] Beeresh Chatrad, Nithin Kammar, Prasanna P Kulkarni, Shrinivas Patil, A study on Minimization of Critical Defects in Casting Process Considering Various Parameters, International Journal of Innovative research in Science, Engineering and Technology,5(2016)8884-8902.

[14] Singh harvir, kumar aman, Minimisation of Casting defects using Taguchi's Method, International Journal of Engineering Science Inovation,5(2016)6-10,ISSN:2319-6734.

[15] Nimbulkar S.L, Dalu R.S, Design Optimization of Gating and Feeding system through Simulation Technique for Sand Casting of Wear Plate,ELSEVIER,8(2016)39-42.

[16] Sarath P, Rathish R, Simulation and experimental validation of feeding efficiency in FG 260 gray cast iron casting, International journal of research and general Science, 2(2014)797-811.

[17] Choudhari C.M, Narkhede B.E, Mahajan S.K, Casting design and Simulation of Cover plate Using Auto CAST-X Software for Defect Minimization with experimental Validation, ELSEVIER,(2014)2211-8128.

[18] Dabade U.A, Bhedasgaonkar R.C,Casting Defect Analysis Using Design of Experiments(DoE) and Computer Aided casting Simulation Technique, ELSEVIER,(2013)2212-8271.

[19] Process Mapping \& procedure Development 2007 Consultas Pvt.Ltd. 